\title{
Las epífitas vasculares en un ambiente urbano están influidas por características del arbolado, el clima y las fuentes de propágulos
}

\author{
M. Virginia González ${ }^{1, \bigotimes}$ \& Sergio J. Ceballos ${ }^{2}$ \\ ${ }^{1}$ Facultad de Ciencias Naturales e Instituto Miguel Lillo, Universidad Nacional de Tucumán (UNT). San Miguel de Tucumán, \\ Tucumán, Argentina. ${ }^{2}$ Instituto de Ecología Regional. Consejo Nacional de Investigaciones Científicas y Técnicas (CONICET) \\ - Universidad Nacional de Tucumán (UNT), Yerba Buena, Tucumán, Argentina.
}

Resumen. El arbolado urbano brinda múltiples beneficios a la población, tales como como la provisión de sombra y la regulación del clima. También puede contribuir a la conservación de plantas nativas de la ecorregión en la que se encuentra la ciudad, aunque existe poca información al respecto. En este trabajo se analizaron la riqueza, la cobertura y la composición del ensamble de epífitas vasculares que habita el arbolado urbano del Gran San Miguel de Tucumán. Para ello se registraron las epífitas en 240 árboles distribuidos en 24 sitios ubicados en las localidades de Horco Molle, El Corte, Yerba Buena y San Miguel de Tucumán. Se registraron las características de los árboles hospedadores (i.e., diámetro a la altura del pecho [DAP], tipo de corteza y número de ramas podadas) y del sitio de muestreo (i.e., distancia a fuentes de propágulos como la Sierra de San Javier y espacios verdes urbanos, temperatura y humedad mediante imágenes satelitales). Se observó que el incremento del DAP y las cortezas rugosas determinaban un incremento significativo en la riqueza y la cobertura de epífitas. Ambas características son conocidas por su importancia en el establecimiento de epífitas al permitir un mayor tiempo de colonización y proveer mayor superficie (DAP), así como por acumular materia orgánica y agua en las grietas de la corteza (rugosidad). La riqueza de epífitas también aumentó en árboles ubicados a menor distancia de la sierra y en sitios con menor temperatura y mayor humedad. La localidad de Horco Molle, más cercana a la sierra, se segregó de otros sectores de la ciudad con respecto a la composición de especies de epífitas. Se observaron interacciones entre arboles hospedadores y epífitas vasculares, en coincidencia con las observadas en bosques prístinos de la sierra. Estos resultados son importantes para el manejo de la vegetación urbana debido a que permiten considerar al arbolado como un aporte importante para la conservación de epífitas nativas de Yungas.

[Palabras clave: conservación, espacios verdes, presión de propágulos, urbanización, Yungas]

Aвstract. Vascular epiphytes in an urban environment are influenced by tree characteristics, climate and propagule sources. Urban trees provide multiple benefits for the citizens such as shadow provision and climate regulation. In addition, it can contribute to the conservation of native plants from the ecoregion where the city is located, although there is not much information about it. In this study, species richness, cover and composition of vascular epiphytes were analyzed in urban trees of Gran San Miguel de Tucumán. We sampled epiphytes over 240 trees in 24 sites located in the localities of Horco Molle, El Corte, Yerba Buena and San Miguel de Tucumán. We recorded characteristics of trees (i.e., diameter at breast height [DBH], bark type and number of pruned branches) and sites (distance from the nearest source of epiphyte propagules such as sierra San Javier and urban green spaces, temperature and humidity using satellite images). Significant increases of species richness and cover of epiphytes were recorded with tree DBH and rough barks. Both features are important for vascular epiphyte establishment because they allow more surface and time available for colonization and a rough bark accumulates water and organic matter. In addition, epiphyte richness increased in trees closer to Sierra de San Javier, and in sites with lower temperature and higher humidity. The locality of Horco Molle, closer to sierra de San Javier, had a different composition of epiphytes compared to the other localities. Interactions between host trees and vascular epiphytes were similar to those observed in pristine forests of sierra de San Javier. These results are relevant for urban vegetation management because they allow us to consider urban trees as an important contribution to the conservation of native Yungas epiphytes.

[Keywords: conservation, green spaces, propagule pressure, urbanization, Yungas]

Editora asociada: Natalia Perez Harguideguy

$\triangle$ virginiagonzalez782@gmail.com 


\section{INTRODUCCIÓN}

La vegetación es uno de los componentes más importantes del ecosistema urbano debido a su aporte en servicios ecosistémicos como la disminución de la temperatura y la contaminación, la influencia positiva en el comportamiento social y la salud, los beneficios estéticos, el aporte a la identidad comunitaria, los beneficios recreacionales y culturales, y el secuestro de carbono (Colding 2007; Niemelä et al. 2010; Santana et al. 2017; Wallace et al. 2017; Spescha 2019). La vegetación en las ciudades se distribuye en plazas, parques, jardines y espacios verdes periurbanos, formando una 'infraestructura verde' que funciona como un sistema ecológico natural o seminatural (Tzoulas et al. 2007; Van der Walt et al. 2015). La vegetación urbana incluye especies nativas y exóticas cuya composición y mantenimiento depende de las características biofísicas y socioeconómicas del entorno (Hope et al. 2008; Knapp et al. 2009; Wallace et al. 2017; Hernández and Villaseñor 2018; Planchuelo et al. 2019; Cao and Natuhara 2020).

Uno de los componentes más importantes de la infraestructura verde de las ciudades es el arbolado urbano (Grau and Kortsarz 2017). La importancia radica no sólo en los servicios ecosistémicos que brinda el arbolado (e.g., la disminución de la isla de calor urbana, sombra), sino también en su rol de mantenimiento de la biodiversidad local. Por ejemplo, el arbolado urbano representa el soporte de lianas, enredaderas y epífitas vasculares en regiones tropicales y subtropicales, y el hábitat y alimento de aves e insectos (Jankowski et al. 2000; Zotz 2016). En un contexto de expansión de las ciudades y pérdida de biodiversidad se vuelve relevante entender como el arbolado urbano contribuye a conservar especies nativas (Knapp et al. 2009; Wallace et al. 2017).

Entre las plantas nativas que habitan sobre el arbolado urbano encontramos a las epífitas vasculares, sobre todo en aquellas ciudades que limitan con ecorregiones boscosas tropicales y subtropicales (Kortsarz and Gómez Romero 2017; Martins et al. 2020). Las epífitas son plantas que desarrollan su ciclo de vida sobre otra planta hospedadora sin extraer de ella ni agua ni nutrientes (Zotz 2016). Son importantes por su rol en las interacciones interespecíficas del dosel, en el incremento de la productividad del ecosistema y por su rol en ciclos hidrológicos y de nutrientes en los bosques (Padmawathe et al. 2004; Higuera and Wolf 2010; Barbosa et al. 2015; Santana et al. 2017). Son un componente importante del ciclo hidrológico de los bosques a través del almacenamiento de agua, transpiración e intercepción de niebla y lluvia (Jarvis 2000; Stanton et al. 2014; Zotz 2016). Históricamente fueron estudiadas en ambientes prístinos como bosques maduros o primarios, y tan sólo en las últimas dos décadas cobró interés su estudio en otro tipo de ecosistemas con influencia antrópica, tales como bosques secundarios y sistemas agroforestales (Vindas 2005; Boelter et al. 2014; Woods et al. 2015; Ceballos 2020).

Existe muy poca información sobre las epífitas que habitan dentro de ambientes urbanos (Martins et al. 2020). Si bien las epífitas colonizan el arbolado urbano principalmente desde bosques adyacentes a las ciudades, también se las cultiva como ornamentales. Por ejemplo, entre las epífitas preferidas como ornamentales se encuentran las orquídeas y las bromelias (Zotz 2016). Es posible que por los elevados niveles de contaminación, la diversidad de epífitas tienda a disminuir en las ciudades (Kortsarz and Gómez Romero 2017). Sin embargo, algunas especies de epífitas como las pertenecientes al género Tillandsia pueden colonizar ambientes urbanos y tolerar altos niveles de contaminación. Algunos estudios observaron que especies epífitas de Tillandsia pueden absorber y acumular contaminantes del aire de origen urbano, agrícola o industrial como sulfuros y metales pesados (Graciano et al. 2003; Bermúdez et al. 2009).

Con respecto a los factores que determinan la presencia de epífitas, se sugirió la importancia de las características del arbolado urbano en el establecimiento exitoso de epífitas vasculares (e.g., Tillandsia recurvata), tales como una corteza rugosa y la edad y la identidad del árbol hospedador (Caldiz et al. 1993; Kortsarz and Gómez Romero 2017). En un área urbana de Minas Gerais (Brasil), Martins et al. (2020) observaron que, en un jardín botánico, la riqueza de epífitas era mayor a medida que aumentaba el perímetro a la altura del pecho y la altura de los árboles que allí crecían. En dicho estudio, las dos especies de árboles que presentaron la mayor diversidad de epífitas correspondieron a una especie exótica y una nativa; los autores concluyeron que las epífitas son generalistas en su relación con los árboles hospedadores. Resultados similares se observaron en el estudio realizado por Bhatt et al. (2015), en el que características del árbol como la corteza $(\mathrm{pH}$, humedad, micro hábitats disponibles, rugosidad) determinaron el nivel 
de agregación y de abundancia de las especies de epífitas vasculares que habitan el arbolado urbano. En el caso específico del Gran San Miguel de Tucumán, una ciudad del noroeste de la Argentina, se sugirió la posibilidad de que la lluvia y la niebla creciente, así como una disminución de la contaminación, determinen un incremento de la abundancia y la riqueza de epífitas desde el centro hacia la sierra de San Javier, donde se encuentran bosques de Yungas habitados por epífitas (Kortsarz and Gómez Romero 2017). De este modo, la presencia de un número importante de epífitas sobre los árboles de la ciudad podría ser indicador de una buena calidad del aire (Kortsarz and Gómez Romero 2017).

Teniendo en cuenta la sensibilidad de las epífitas a las perturbaciones antrópicas que afectan su dispersión y las condiciones microclimáticas idóneas para su desarrollo, es esperable que diferentes factores alteren su riqueza y su abundancia dentro de las ciudades (Padmawathe et al. 2004; Yang et al. 2015; Böhnert et al. 2016; Becker et al. 2017; Guida-Johnson et al. 2017). Debido a la modificación y la homogeneización de la vegetación del entorno urbano, se espera que el ensamble de epífitas dentro de las ciudades muestre aspectos diferentes a lo que se conoce para ecosistemas boscosos donde se las estudió tradicionalmente (Bhatt et al. 2015). Además de las características de los árboles hospedadores que influyen sobre las epífitas, otros aspectos pueden cambiar su riqueza y abundancia, como la densidad de árboles, la distancia a fuente de propágulos y las condiciones de temperatura y humedad que cambian en un entorno urbano (Padmawathe et al. 2004; Ceballos et al. 2016; Victoriano-Romero et al. 2017; Planchuelo et al. 2019). En particular, en los bosques las epífitas están expuestas a disturbios eventuales como la caída de árboles, de partes de corteza o de ramas (Zotz 2016), mientras que en las ciudades los disturbios que pueden afectar a las epífitas son la caída de árboles y la poda anual de ramas.

En este estudio analizamos la riqueza, la cobertura y la composición de las epífitas vasculares que habitan en el arbolado urbano del Gran San Miguel de Tucumán (Tucumán, Argentina). Los objetivos específicos son: 1) analizar la influencia de las características de los árboles (i.e., diámetro a la altura del pecho [DAP], la rugosidad de la corteza y el número de ramas podadas) y de la cercanía a fuentes de propágulos (i.e., la sierra de San Javier y espacios verdes urbanos) sobre las epífitas, a escala del árbol individual, 2) evaluar la influencia de las condiciones climáticas (i.e., temperatura y humedad ambiental) sobre la riqueza y la cobertura de epífitas, a escala del sitio (i.e., suma de los ensambles de epífitas de todos los árboles relevados en un sitio de muestreo), y 3) describir patrones generales de la composición de especies de epífitas en diferentes sectores del Gran San Miguel de Tucumán. Las predicciones en relación con cada objetivo específico son: 1A) la riqueza y la cobertura de epífitas disminuirán en árboles alejados de fuentes de propágulos de epífitas (i.e., la sierra de San Javier y espacios verdes urbanos), 1B) la riqueza y la cobertura de epífitas será mayor en árboles con mayor DAP (diámetro a la altura del pecho) y corteza rugosa debido a que representan condiciones más propicias para el establecimiento y crecimiento de epífitas (i.e. árboles con mayor superficie, longevidad y grietas que acumulan materia orgánica), 1C) la riqueza y la cobertura de epífitas disminuirá en árboles con mayor número de podas, lo que implica una reducción del hábitat disponible para las epífitas; 2) la riqueza y la cobertura de epífitas disminuirán en sitios con mayor temperatura y menor humedad debido a que al habitar en la corteza de los árboles y tener menor acceso al agua, muchas especies de epífitas son sensibles a las condiciones de desecación; y 3) la composición de especies diferirá entre distintos sectores del Gran San Miguel de Tucumán en función de su cercanía a la sierra de San Javier y a su grado de urbanización.

\section{Materiales y Métodos}

\section{Área de estudio}

Este estudio se llevó a cabo en el Gran San Miguel de Tucumán $\left(26^{\circ} 49^{\prime} \mathrm{S}-6^{\circ} 13^{\prime} \mathrm{O}\right)$, ciudad que cuenta con una población cercana al millón de habitantes (929468 habitantes) (INDEC 2010), lo cual representa casi 60\% de la población de la provincia de Tucumán (Cuozzo and Castañeda Nordmann 2019). El Gran San Miguel de Tucumán posee un clima subtropical con estación seca (inviernos secos, veranos lluviosos) (Bomba et al. 2007). Las dos ciudades más densamente pobladas del Gran San Miguel de Tucumán son San Miguel de Tucumán y Yerba Buena, representando un gradiente de urbanización que decrece hacia el oeste, en dirección hacia la sierra de San Javier (Haedo et al. 2017; Cuozzo and Castañeda Nordmann 2019). San Miguel de Tucumán es la capital de la provincia, la ciudad más 
poblada del Gran San Miguel de Tucumán; su urbanización consiste en una alta densidad de viviendas y edificios en altura, sobre todo en la zona céntrica. Yerba Buena se encuentra al oeste del Gran San Miguel de Tucumán, limita con la sierra de San Javier y debido a su crecimiento relativamente reciente, a su código de planeamiento urbano y a sus condiciones socioeconómicas, cuenta con viviendas bajas, con jardines amplios y un importante arbolado urbano (Oltra-Carrió et al. 2010). Hacia el oeste de Yerba Buena se encuentran las localidades de El Corte y Horco Molle, que representan el límite natural-urbano entre el Gran San Miguel de Tucumán y la sierra de San Javier (Grau 2010). La característica urbana de El Corte y Horco Molle es su menor densidad de viviendas, que se encuentran entre parches de bosques de Yungas y campos de cultivo (Bomba et al. 2007; Haedo et al. 2010).

\section{Protocolo de muestreo}

Dentro del Gran San Miguel de Tucumán se seleccionaron 24 puntos a distintas distancias con respecto a la sierra de San Javier, en Horco Molle, El Corte, Yerba Buena y San Miguel de Tucumán (Material Suplementario 1). En relación con el tamaño de las localidades y las ciudades del aglomerado urbano, se muestrearon 2 puntos en Horco Molle, 1 punto en El Corte, 9 puntos en Yerba Buena y 12 puntos en San Miguel de Tucumán. En cada punto se registró la posición geográfica (nombre y número de calle) y se seleccionaron 10 árboles contiguos con un DAP'10 cm (diámetro a la altura del pecho). Dado que por las características de la ciudad no se puede delimitar una parcela de muestreo de un tamaño determinado, decidimos mantener constante el número de árboles para representar un esfuerzo de muestreo similar en los diferentes puntos. Además, debido a la baja riqueza de especies de epífitas esperada en el arbolado urbano, consideramos que 10 árboles representaban un número adecuado para muestrear la mayor parte del ensamble de epífitas. Se seleccionaron los primeros 10 árboles contiguos a partir de la esquina oeste en cada punto de muestreo. En cada árbol se identificaron las especies de epífitas hospedadas considerando holoepífitas, epífitas facultativas y epífitas accidentales. Sin embargo, en los análisis posteriores, tuvimos en cuenta sólo a las holoepífitas y a las epífitas facultativas, debido a que las epífitas accidentales por lo general son plantas terrestres que ocasionalmente pueden germinar y crecer sobre un árbol, y no son verdaderas epífitas. También se estimó la cobertura de epífitas sobre cada árbol empleando binoculares y siguiendo una escala de Braun-Blanquet modificada, asignando a cada árbol un valor de cobertura de acuerdo con 10 niveles: 1: 1-10\%, 2: 11-20\%, 3: $21-30 \%$, 4: 31-40\%, 5: 41-50\%, 6: 51-60\%, 7: 61-70\%, 8: $71-80 \%$, 9: $81-90 \%$ y 10: $91-100 \%$. Respecto de las características de cada árbol, se midió su DAP, se contó el número de ramas podadas y se determinó la rugosidad de su corteza por medio de observaciones, teniendo en cuenta cuatro tipos: corteza lisa o exfoliante, ligeramente rugosa o agrietada, rugosa o agrietada y corteza con mamelones o aguijones. Con respecto al número de ramas podadas, contamos las cicatrices de podas de ramas primarias y secundarias en cada individuo arbóreo. Empleando la regla de Google Earth se midieron las distancias de los árboles con respecto a la sierra de San Javier y al espacio verde más cercano (plazas o parques) a partir de imágenes satelitales.

\section{Proporción de vegetación urbana, temperatura y humedad}

Para cada sitio se obtuvo información de las variables proporción de vegetación urbana, temperatura y humedad ambiental utilizando imágenes satelitales. Se emplearon imágenes Landsat-8 del Gran San Miguel de Tucumán correspondientes al lapso entre el 1 de julio y el 30 de agosto de 2019, abarcando el período de muestreo (estación seca) y adicionando escenas de la estación húmeda. A partir de esta colección, mediante Google Earth Engine se obtuvo una única imagen promedio que se usó para determinar un área de influencia de $350 \mathrm{~m}$ de radio alrededor de cada sitio de muestreo, empleando QGIS (QGIS Development Team 2016). Seleccionamos $350 \mathrm{~m}$ para incluir un número significativo de píxeles, de $30 \mathrm{~m}$ cada uno, que representaran las características urbanas del área de influencia (i.e., proporción de vegetación en relación con la superficie construida).

Para obtener la variable proporción de vegetación urbana calculamos, en primer lugar, el NDVI promedio (Normalized Difference Vegetation Index) para cada sitio y su área de influencia. El NDVI es un parámetro biofísico muy utilizado para detectar biomasa fotosintéticamente activa, basado en la absorción y la reflectancia lumínica de las plantas. Está asociado al nivel de absorción de luz roja por la clorofila en las plantas y la reflectancia en la longitud 
de onda del infrarrojo cercano, y se estima como: NDVI=(NIR-RED)/(NIR+RED), donde NIR es la banda del infrarrojo cercano y RED es la del rojo (bandas 5 y 4, respectivamente, en Landsat 8) (Bhandari et al. 2012; Arteaga et al. 2019). Toma valores entre -1 y 1 ; los más altos denotan una vegetación saludable y vigorosa (Rosell and Vicente 2016). Con el objetivo de representar la vegetación urbana de diferentes espacios (e.g., parques, plazas, arbolado urbano y jardines) se empleó la técnica de detección de vegetación por intervalo de NDVI (Gross 2005; Bhandari et al. 2012; Senanayake et al. 2013; Bardhan et al. 2016; Hashim et al. 2019). En QGIS se dividió el rango de valores de NDVI en cuantiles $(\mathrm{Q} 1=-$ $0.4 ; \mathrm{Q} 2=0.6 ; \mathrm{Q} 3=0.9$ ) y se tomaron los cuantiles 0.6 y 0.9 como zonas de vegetación mediaalta (El-Gammal et al. 2014). Para obtener la proporción de vegetación urbana, luego de reclasificar la imagen teniendo en cuenta estos valores se dividió la superficie de vegetación en la superficie de área de influencia con la calculadora de campos de QGIS.

La temperatura para cada sitio y su área de influencia se calculó como temperatura de superficie (Land Surface Temperature, LST), la cual se encuentra muy asociada a la presencia de vegetación circundante (Gioia et al. 2014). Consiste, en primer lugar, en estimar el valor de TOA (Top of the Atmosphere Spectral Radiance) para los píxeles de la imagen satelital base. Luego se transforman a valores de radiancia de temperatura, expresados en grados Celsius (Brightness Temperature, BT). Finalmente, la fórmula para calcular la temperatura de superficie incluye entre sus parámetros a BT y a $\varepsilon$ (emisividad de superficie calculada en base al NDVI) (Avdan and Jovanovska 2016).

La humedad ambiental para casa sitio y su área de influencia se calculó por medio del NDMI (Normalized Difference Moisture Index), que calcula la humedad a partir del contenido de agua en la vegetación (Rahman and Mesev 2019). Al igual que el NDVI, toma valores entre 1 y -1 , con valores mayores cuando hay un mayor contenido de agua en la vegetación. Se calculó con la fórmula NDMI=(NIRSWIR)/(NIR+SWIR), donde SWIR es la banda correspondiente al infrarrojo de onda media (banda 6 en Landsat 8).

\section{Análisis estadísticos}

Para analizar la influencia de diferentes variables sobre la riqueza de especies y la cobertura de epífitas en el arbolado urbano utilizamos dos escalas de análisis: el árbol individual y el sitio o punto de muestreo. Para ello empleamos el marco conceptual de Mendieta-Leiva y Zotz (2015), que considera al árbol individual o al conjunto de árboles (sitio de muestreo) como unidad de muestreo o análisis para ensambles de epífitas vasculares. Seleccionamos este esquema teniendo en cuenta, además, la escala de influencia de las variables sobre las epífitas. Por ejemplo, el tipo de corteza o el DAP de un árbol podrían influir sobre las epífitas a escala del árbol individual, mientras que variables ambientales como la temperatura o la humedad podrían influir a una escala mayor (sitio de muestreo). Ambos análisis se realizaron con modelos lineales generalizados mixtos (glmm), con una distribución de errores binomial negativa en R (R Core Team 2021); se usaron las librerías lme4 (Bates et al. 2015) y MuMIn (Barton 2009). La evaluación de los modelos se realizó mediante gráficos de residuales vs. valores predichos.

Utilizando como unidad de análisis al árbol individual, analizamos la variación de la riqueza de especies y la cobertura de epífitas (variables de respuesta) en relación con las variables explicativas distancia a la sierra de San Javier, distancia a espacios verdes, DAP del árbol, tipo de corteza y número de ramas podadas (objetivo 1). El conjunto de datos consistió en 240 árboles (incluyendo tanto hospedadores como árboles sin epífitas); este set se utilizó para realizar un glmm para cada variable de respuesta por separado. Antes de realizar los modelos evaluamos la colinealidad entre las variables explicativas continuas, que resultaron en coeficientes de correlaciones bajos entre todas las variables (Tabla S1, Material Suplementario 2). En cada GLMM se incluyó al sitio como efecto aleatorio debido al diseño de muestreo (i.e., 10 árboles muestreados por sitio). Dado que el tipo de corteza es una variable cualitativa, realizamos análisis de Tukey a posteriori para evaluar diferencias entre las categorías de corteza, con la librería emmeans (Lenth 2020).

Inicialmente, para el objetivo 2 se planteó evaluar cómo influyen diferentes variables (i.e., distancia a la sierra de San Javier, proporción de vegetación urbana, temperatura y humedad de cada sitio) sobre la riqueza y la cobertura de epífitas (variables de respuesta). Antes de los análisis realizamos correlaciones múltiples y observamos que a medida que aumenta la distancia a la sierra de San Javier disminuye significativamente 
la proporción de vegetación urbana $(\mathrm{r}=-0.83)$. También observamos altas correlaciones de estas variables con la temperatura y la humedad de cada sitio (Tabla S2, Material Suplementario 2). Por esta razón decidimos mantener estas variables en los análisis y eliminar las variables distancia a la sierra de San Javier y proporción de vegetación urbana. Como la temperatura y la humedad cambian a una escala mayor (e.g., en diferentes sectores de la ciudad de acuerdo con la proporción de espacios verdes, la densidad del arbolado y la superficie construida), seleccionamos al sitio y no al árbol individual como unidad de análisis. La temperatura (medida como LST) varía entre 16.72 y $20.37^{\circ} \mathrm{C}$, y la humedad (medida como NDMI) entre 0.81 y 0.28 , en sectores menos y más urbanizados, respectivamente. La base de datos para los glmm incluyó información de temperatura y humedad ambiental para los 24 sitios relevados en el Gran San Miguel de Tucumán. Para las variables de respuesta consideramos la riqueza total del ensamble de epífitas y la suma de las coberturas de epífitas de los 10 árboles muestreados por sitio. La ciudad o localidad donde estaban ubicados los sitios de muestreo (i.e., Horco Molle, El Corte, Yerba Buena y San Miguel de Tucumán) fue considerada como efecto aleatorio en cada glmm.

Para analizar la composición de especies de epífitas en el arbolado urbano del Gran San Miguel de Tucumán (objetivo 3) utilizamos un análisis multivariado NMDS (NonMetrical Multidimensional Scaling) de la librería vegan (Oksanen et al. 2007). El NMDS es un método que permite condensar información multidimensional (e.g., múltiples variables, sitios o especies) en un ordenamiento de 2 ó 3 dimensiones. En el ordenamiento, mientras más cercanos se encuentran dos puntos, más similares son en cuanto a las variables o especies incluidas. Además de su utilidad para analizar la composición de especies, seleccionamos este análisis debido a que permite incluir datos que no cumplen con la distribución normal. Este es el caso de nuestros datos puesto que existen pocas especies muy abundantes y varias especies con bajo número de registros. La matriz utilizada para el NMDS consistió en filas de individuos arbóreos como unidad de análisis y columnas de especies de epífitas verdaderas o facultativas registradas en cada árbol. Incluimos sólo a los árboles que hospedaron epífitas $(n=203)$ y descartamos a las epífitas registradas como accidentales. En el interior de la matriz multiplicamos la cobertura de las especies de epífitas por el DAP del árbol hospedador, debido a que un mismo valor de cobertura puede representar una mayor o menor abundancia de epífitas de acuerdo con el tamaño del árbol. La medida de distancia seleccionada para el NMDS fue Bray Curtis porque los valores en la matriz son similares a una medida de abundancia relativa de las especies. Seleccionamos una representación de dos dimensiones debido a que el stress final (un índice de concordancia entre las distancias en el espacio de ordenamiento y las distancias en la matriz de Bray Curtis) fue 17.58 (para bases de datos en ecología se recomienda un valor $<20$ ).

\section{Resultados}

Se hizo un relevamiento de 240 individuos arbóreos pertenecientes a 31 especies (Tabla 1 ), en los cuales se identificaron 18 especies de holoepífitas y epífitas facultativas pertenecientes a las familias Bromeliaceae, Polypodiaceae, Piperaceae y Cactaceae (Tabla 2). Del total de árboles relevados, $85 \%$ fueron hospedadores de al menos una especie de epífita. Las especies de árboles más frecuentes fueron Jacaranda mimosifolia (40 individuos), Handrohanthus impetiginosus (46), Bahuinia variegata (12), Handrohanthus ochraceus (24), Platanus acerifolia (9) y Citrus aurantium (9). El 74\% de las especies arbóreas y el $46 \%$ de los individuos arbóreos registrados eran exóticos. Dentro de las especies exóticas, $76 \%$ de los individuos fueron colonizados por al menos una epífita y tuvieron una cobertura promedio de 2 en la escala de Braun-Blanquet (11-20\% de la corteza de los árboles cubierta por epífitas). Mientras tanto, entre las especies nativas, 91\% hospedó al menos una especie de epífita, con una cobertura promedio de 4 en la escala de Braun-Blanquet (31-40\% de la corteza de los árboles cubierta por epífitas) (Tabla 1). Las especies de epífitas más frecuentes fueron Tillandsia recurvata (166 registros), Tillandsia didisticha (131), Pleopeltis tweediana (117) y Tillandsia tricholepis (107) (Tabla 2).

La riqueza de especies de epífitas aumentó significativamente con el DAP de los árboles y con la cercanía a la sierra de San Javier, y exhibió una tendencia a aumentar a menor distancia a espacios verdes urbanos (Tabla 3; Figura 1). La riqueza de epífitas aumentó con el DAP en las localidades de Horco Molle, El Corte y en la ciudad de Yerba Buena, y no así en San Miguel de Tucumán (Figura 2). Por su parte, la cobertura de epífitas 
Tabla 1. Lista de especies de árboles relevados, con su correspondiente familia y número de individuos. La condición para cada especie de árbol hace referencia a si son nativas (N) o exóticas (E) en la provincia de Tucumán (Argentina).

Table 1. Total number of tree species, including their family and number of individuals. The condition of each tree correspond to their native $(\mathrm{N})$ or exotic (E) status in the province of Tucuman (Argentina).

\begin{tabular}{|c|c|c|c|c|c|c|c|c|}
\hline Familia & Especie & Condición & $\begin{array}{l}\text { Nro. de } \\
\text { individuos }\end{array}$ & $\begin{array}{l}\text { Individuos } \\
\text { que } \\
\text { hospedaron } \\
\text { epífitas (\%) }\end{array}$ & $\begin{array}{c}\text { Árboles } \\
\text { con corteza } \\
\text { rugosa o } \\
\text { agrietada } \\
(\%)\end{array}$ & $\begin{array}{l}\text { Árboles } \\
\text { con corteza } \\
\text { ligeramente } \\
\text { rugosa o } \\
\text { agrietada } \\
(\%)\end{array}$ & $\begin{array}{c}\text { Árboles con } \\
\text { corteza lisa } \\
\text { o exfoliante } \\
(\%)\end{array}$ & $\begin{array}{l}\text { Árboles con } \\
\text { corteza con } \\
\text { aguijones o } \\
\text { mamelones }\end{array}$ \\
\hline Altingiaceae & Liquidambar styraciflua & $\mathrm{E}$ & 4 & 75 & 25 & 50 & 25 & 0 \\
\hline Anacardiaceae & Schinus areira & $\mathrm{N}$ & 1 & 100 & 0 & 100 & 0 & 0 \\
\hline Arecaceae & Syagrus romanzoffiana & E & 3 & 66.7 & 0 & 0 & 100 & 0 \\
\hline Bignoniaceae & Handroanthus chrysotrichus & $\mathrm{E}$ & 1 & 100 & 100 & 0 & 0 & 0 \\
\hline Bignoniaceae & Handroanthus impetiginosus & $\mathrm{N}$ & 46 & 97.8 & 95.7 & 4.34 & 0 & 0 \\
\hline Bignoniaceae & Handroanthus ochraceus & $\mathrm{E}$ & 24 & 91.7 & 91.6 & 8.3 & 0 & 0 \\
\hline Bignoniaceae & Jacaranda mimosifolia & $\mathrm{N}$ & 40 & 98 & 90 & 10 & 0 & 0 \\
\hline Fabaceae & Anadenanthera colubrina & $\mathrm{N}$ & 6 & 87.5 & 12.5 & 0 & 0 & 87.5 \\
\hline Fabaceae & Bauhinia forticata & $\mathrm{E}$ & 1 & 100 & 100 & 0 & 0 & 0 \\
\hline Fabaceae & Bauhinia variegata & $\mathrm{E}$ & 12 & 50 & 0 & 66.7 & 33.3 & 0 \\
\hline Fabaceae & Ceiba chodatii & $\mathrm{N}$ & 2 & 50 & 0 & 0 & 60 & 40 \\
\hline Fabaceae & Enterolobium contortisiliquum & $\mathrm{N}$ & 1 & 100 & 0 & 0 & 100 & 0 \\
\hline Fabaceae & Erythrina speciosa & $\mathrm{N}$ & 2 & 0 & 100 & 0 & 0 & 0 \\
\hline Fabaceae & Tipuana tipu & $\mathrm{N}$ & 9 & 66.7 & 77.8 & 22.2 & 0 & 0 \\
\hline Fabaceae & Peltophorum dubium & $\mathrm{E}$ & 1 & 100 & 100 & 0 & 0 & 0 \\
\hline Fagaceae & Quercus robur & E & 2 & 100 & 100 & 0 & 0 & 0 \\
\hline Lauraceae & Ocotea porphyria & $\mathrm{N}$ & 1 & 100 & 100 & 0 & 0 & 0 \\
\hline Lauraceae & Cinnamomun glanduliferum & $\mathrm{E}$ & 5 & 80 & 20 & 80 & 0 & 0 \\
\hline Lauraceae & Persea americana & E & 1 & 100 & 100 & 0 & 0 & 0 \\
\hline Malvaceae & Brachychiton populneus & $\mathrm{E}$ & 1 & 100 & 0 & 100 & 0 & 0 \\
\hline Meliaceae & Cedrela angustifolia & $\mathrm{N}$ & 8 & 100 & 100 & 0 & 0 & 0 \\
\hline Moraceae & Ficus benjamina & $\mathrm{E}$ & 4 & 50 & 0 & 25 & 75 & 0 \\
\hline Moraceae & Morus alba & E & 6 & 83.3 & 83.3 & 16.7 & 0 & 0 \\
\hline Myrtaceae & Acca sellowiana & E & 2 & 100 & 0 & 0 & 100 & 0 \\
\hline Myrtaceae & Eucalyptus camaldulensis & E & 2 & 100 & 50 & 0 & 50 & 0 \\
\hline Oleaceae & Fraxinus penssylvanica & E & 5 & 100 & 80 & 20 & 0 & 0 \\
\hline Oleaceae & Ligustrum lucidum & E & 5 & 100 & 20 & 40 & 40 & 0 \\
\hline Platanaceae & Platanus acerifolia & E & 9 & 0 & 0 & 0 & 100 & 0 \\
\hline Pinaceae & Pinus elliottii & $\mathrm{E}$ & 2 & 100 & 100 & 0 & 0 & 0 \\
\hline Polygonaceae & Ruprechtia laxiflora & $\mathrm{N}$ & 1 & 100 & 100 & 0 & 0 & 0 \\
\hline Proteaceae & Grevillea robusta & $\mathrm{E}$ & 4 & 100 & 100 & 0 & 0 & 0 \\
\hline Rutaceae & Citrus aurantium & E & 9 & 66.7 & 0 & 0 & 100 & 0 \\
\hline Salicaceae & Populus deltoides & $\mathrm{E}$ & 3 & 100 & 100 & 0 & 0 & 0 \\
\hline Salicaceae & Salix humboldtiana & $\mathrm{N}$ & 11 & 100 & 100 & 0 & 0 & 0 \\
\hline Ulmaceae & Ulmus pumila & $\mathrm{E}$ & 4 & 100 & 100 & 0 & 0 & 0 \\
\hline
\end{tabular}

aumentó significativamente con el DAP de los árboles. La riqueza del ensamble de epífitas también aumentó significativamente en sitios de la ciudad con menor temperatura y mayor humedad ambiental, mientras que la cobertura de epífitas por sitio no cambió con respecto a las variables ambientales (Tabla 3). Tanto la riqueza como la cobertura de epífitas fueron mayores en árboles con corteza rugosa o agrietada, en comparación con árboles con cortezas ligeramente rugosas o agrietadas, lisas o exfoliantes, y con aguijones o mamelones (Figura 3).
En cuanto a la composición de epífitas en diferentes sectores de la ciudad, los árboles muestreados en Horco Molle se segregaron en el NMDS con respecto a El Corte, Yerba Buena y San Miguel de Tucumán (Figura 4). Los árboles hospedadores de Horco Molle se separaron junto a las especies Aechmea distichanta, Vriesea friburgensis, Phlebodium areolatum, Peperomia incresens, Peperomia tetraphylla, Rhipsalis lorentziana y Tillandsia tenuifolia. Los árboles hospedadores de El Corte, Yerba Buena y San Miguel de Tucumán no se separaron entre sí en cuanto a la composición de especies de 
Tabla 2. Lista de especies de epífitas registradas en el arbolado urbano del Gran San Miguel de Tucumán (Argentina).

Table 2. List of epiphyte species recorded in the urban trees of Gran San Miguel de Tucuman (Argentina).

\begin{tabular}{|c|c|c|c|c|}
\hline Familia & Especies epífitas & Tipo & $\begin{array}{l}\text { Número de } \\
\text { registros }\end{array}$ & Código \\
\hline Bromeliaceae & Tillandsia didisticha & Holoepífita & 131 & Tdid \\
\hline Bromeliaceae & Aechmea distichanta & Epífita facultativa & 20 & Adis \\
\hline Bromeliaceae & Tillandsia tricholepis & Holoepífita & 107 & Ttri \\
\hline Bromeliaceae & Tillandsia ixioides & Holoepífita & 9 & Tixi \\
\hline Bromeliaceae & Tillandsia lorentziana & Holoepífita & 11 & Tlor \\
\hline Bromeliaceae & Tillandsia recurvata & Holoepífita & 166 & Trec \\
\hline Bromeliaceae & Tillandsia reichenbachii & Holoepífita & 4 & Trei \\
\hline Bromeliaceae & Tillandsia tenuifolia & Holoepífita & 48 & Tten \\
\hline Bromeliaceae & Vriesea friburgensis & Holoepífita & 3 & Vfri \\
\hline Cactaceae & Rhipsalis floccosa & Holoepífita & 27 & Rflo \\
\hline Cactaceae & Rhipsalis lumbricoides & Holoepífita & 22 & Rlum \\
\hline Cactaceae & Rhipsalis lorentziana & Holoepífita & 2 & Rlor \\
\hline Polypodiaceae & Microgramma squamulosa & Holoepífita & 56 & Msqu \\
\hline Polypodiaceae & Pleopeltis tweediana & Holoepífita & 117 & Ptwe \\
\hline Bignoniaceae & Handrohanthus sp. & Epífita accidental & 1 & - \\
\hline Bignoniaceae & Jacaranda sp. & Epífita accidental & 1 & - \\
\hline Apiaceae & No identificada & Epífita accidental & 1 & - \\
\hline- & No identificada & Epífita accidental & 7 & - \\
\hline Piperaceae & Peperomia increscens & Holoepífita & 3 & Pinc \\
\hline Piperaceae & Peperomia tetraphylla & Holoepífita & 1 & Ptet \\
\hline Piperaceae & Peperomia theodori & Holoepífita & 7 & Pthe \\
\hline Polypodiaceae & Phlebodium areolatum & Holoepífita & 2 & Pare \\
\hline Piperaceae & Piper tucumanum & Epífita accidental & 1 & - \\
\hline
\end{tabular}

Tabla 3. Resultados de los modelos lineales generalizados mixtos para explicar la variación de la riqueza de especies y cobertura de epífitas que habitan el arbolado urbano del Gran San Miguel de Tucumán (Argentina), a escala del árbol individual y del sitio de muestreo.

Table 3. Results of generalized lineal mixed models to explain variations in species richness and cover of epiphytes in the urban trees of Gran San Miguel de Tucuman (Argentina), at the individual tree and sampling site scales.

\begin{tabular}{|c|c|c|c|c|c|c|c|}
\hline $\begin{array}{l}\text { Unidad de } \\
\text { análisis }\end{array}$ & $\begin{array}{l}\text { Variable de } \\
\text { respuesta }\end{array}$ & $\begin{array}{l}\mathrm{R}^{2} \text { marginal - } \\
\mathrm{R}^{2} \text { condicional }\end{array}$ & Variables explicativas & Estimador & $\begin{array}{c}\text { Error } \\
\text { estándar }\end{array}$ & Z & $P$ \\
\hline \multirow[t]{10}{*}{ Árbol } & \multirow{5}{*}{$\begin{array}{l}\text { Riqueza de } \\
\text { epífitas }\end{array}$} & \multirow[t]{5}{*}{$0.42-0.46$} & DAP & 0.008 & 0.002 & 5.371 & $0.001^{*}$ \\
\hline & & & Distancia a la Sierra de San Javier & -0.029 & 0.013 & -2.239 & $0.025^{*}$ \\
\hline & & & Número de ramas podadas & 0.008 & 0.006 & 1.301 & 0.193 \\
\hline & & & Distancia a espacios verdes & -0.001 & 0.001 & -1.859 & 0.063 \\
\hline & & & Rugosidad & 0.764 & 0.161 & 4.757 & $0.001^{*}$ \\
\hline & \multirow{5}{*}{$\begin{array}{l}\text { Cobertura de } \\
\text { epífitas }\end{array}$} & \multirow[t]{5}{*}{$0.34-0.58$} & DAP & 0.011 & 0.002 & 6.322 & $0.001^{*}$ \\
\hline & & & Distancia a la Sierra de San Javier & 0.012 & 0.026 & 0.448 & 0.654 \\
\hline & & & Número de ramas podadas & 0.014 & 0.012 & 1.161 & 0.246 \\
\hline & & & Distancia a espacios verdes & -0.001 & 0.001 & -1.158 & 0.247 \\
\hline & & & Rugosidad & 1.056 & 0.196 & 5.377 & $0.001^{*}$ \\
\hline \multirow[t]{4}{*}{ Sitio } & \multirow{2}{*}{$\begin{array}{l}\text { Riqueza de } \\
\text { epífitas }\end{array}$} & \multirow[t]{2}{*}{$0.42-0.42$} & Temperatura & -0.284 & 0.037 & -7.699 & $0.001^{*}$ \\
\hline & & & Humedad & 0.909 & 0.437 & 2.083 & $0.037^{*}$ \\
\hline & \multirow{2}{*}{$\begin{array}{l}\text { Cobertura de } \\
\text { epífitas }\end{array}$} & \multirow[t]{2}{*}{$0.13-0.13$} & Temperatura & -0.349 & 0.196 & -1.776 & 0.075 \\
\hline & & & Humedad & -0.766 & 1.202 & -0.637 & 0.524 \\
\hline
\end{tabular}


A
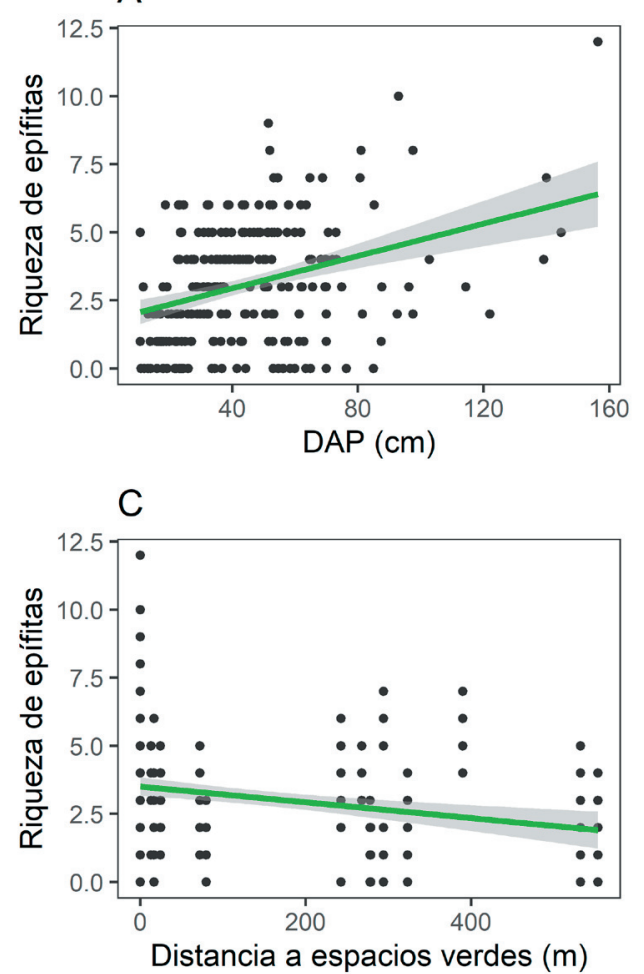

B

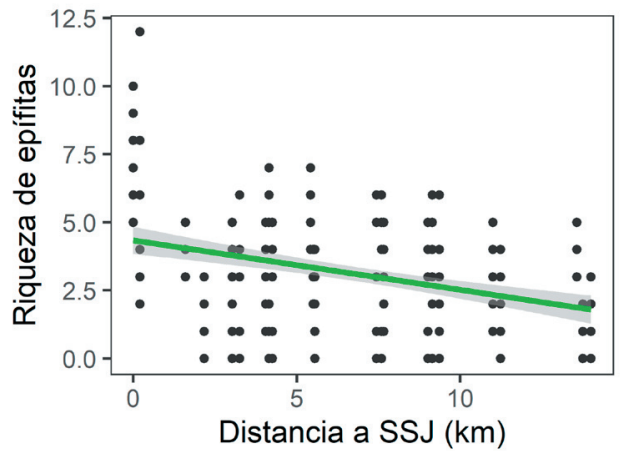

$\mathrm{D}$

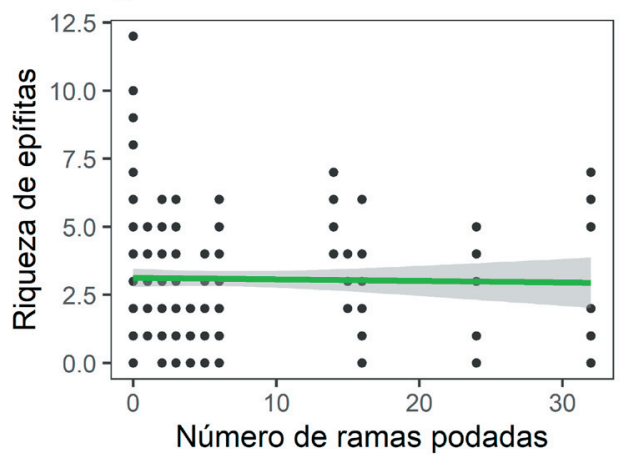

Figura 1. Variación de la riqueza de especies de epífitas respecto al DAP del árbol (A), la distancia a la Sierra de San Javier (B), la distancia a espacios verdes urbanos (C) y el número de ramas podadas (D). Cada punto en los gráficos representa a un árbol hospedador de epífitas.

Figure 1. Epiphytes species richness variation with tree DBH (A), distance to Sierra de San Javier (B), distance to urban green spaces (C) and number of pruned tree branches (D). Each point in the figure represents a host tree.
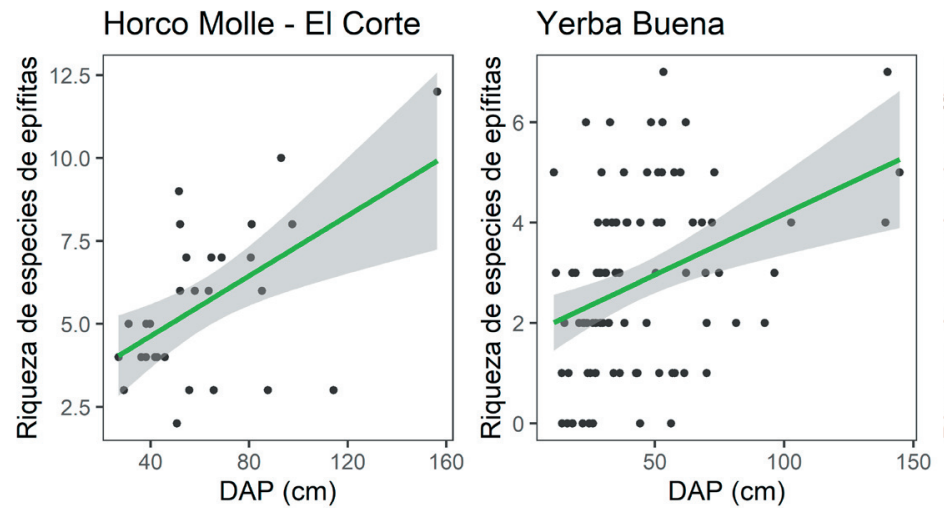

San Miguel de Tucumán

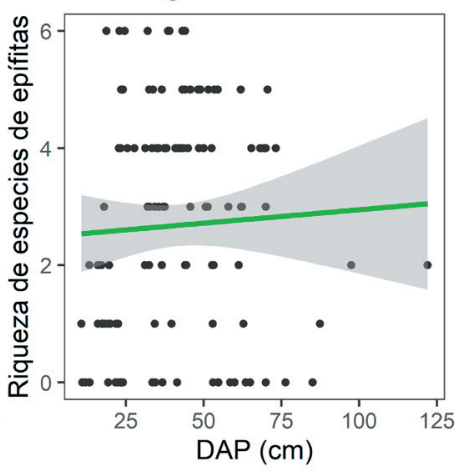

Figura 2. Relación entre la riqueza de especies de epífitas y el DAP de los árboles en las localidades de Horco Molle y El Corte y en las ciudades de Yerba Buena y San Miguel de Tucumán. Notar la disminución del DAP máximo de los árboles desde Horco Molle-El Corte hasta San Miguel de Tucumán. Incluimos un único gráfico para Horco Molle y El Corte por la cercanía entre ambas localidades y por el menor número de árboles muestreados, en comparación con las ciudades de Yerba Buena y San Miguel de Tucumán.

Figure 2. Relationship between epiphyte species richness and tree DBH in the localities of Horco Molle and El Corte and in the cities of Yerba Buena and San Miguel de Tucumán. Note how maximum tree DBH decrease from Horco Molle-El Corte to San Miguel de Tucumán. We include a single graph for Horco Molle and El Corte due to the proximity of both localities and the smaller number of trees, compared to the cities of Yerba Buena and San Miguel de Tucumán. 


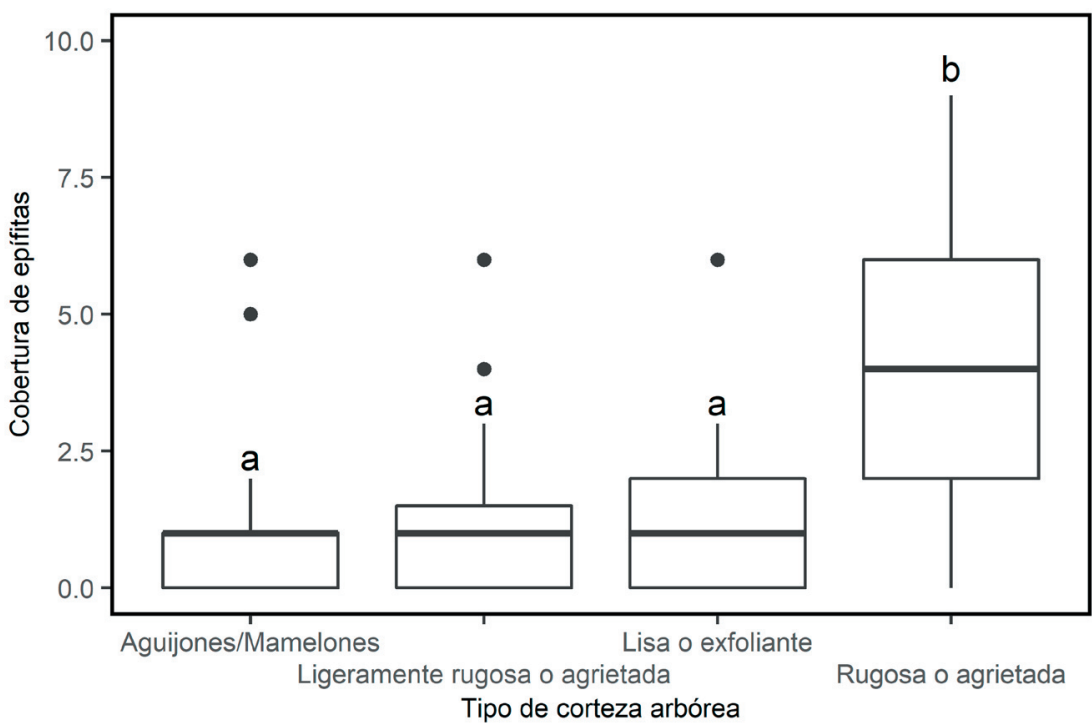

Figura 3. Categorías de Braun-Blanquet para la cobertura de epífitas en relación con diferentes tipos de corteza arbórea. Las letras arriba de las cajas indican diferencias significativas entre los tipos de corteza.

Figure 3. Braun-Blanquet categories for epiphytes cover in relation with different types of tree bark. Letters above the boxplots indicate significant differences between tree bark types.

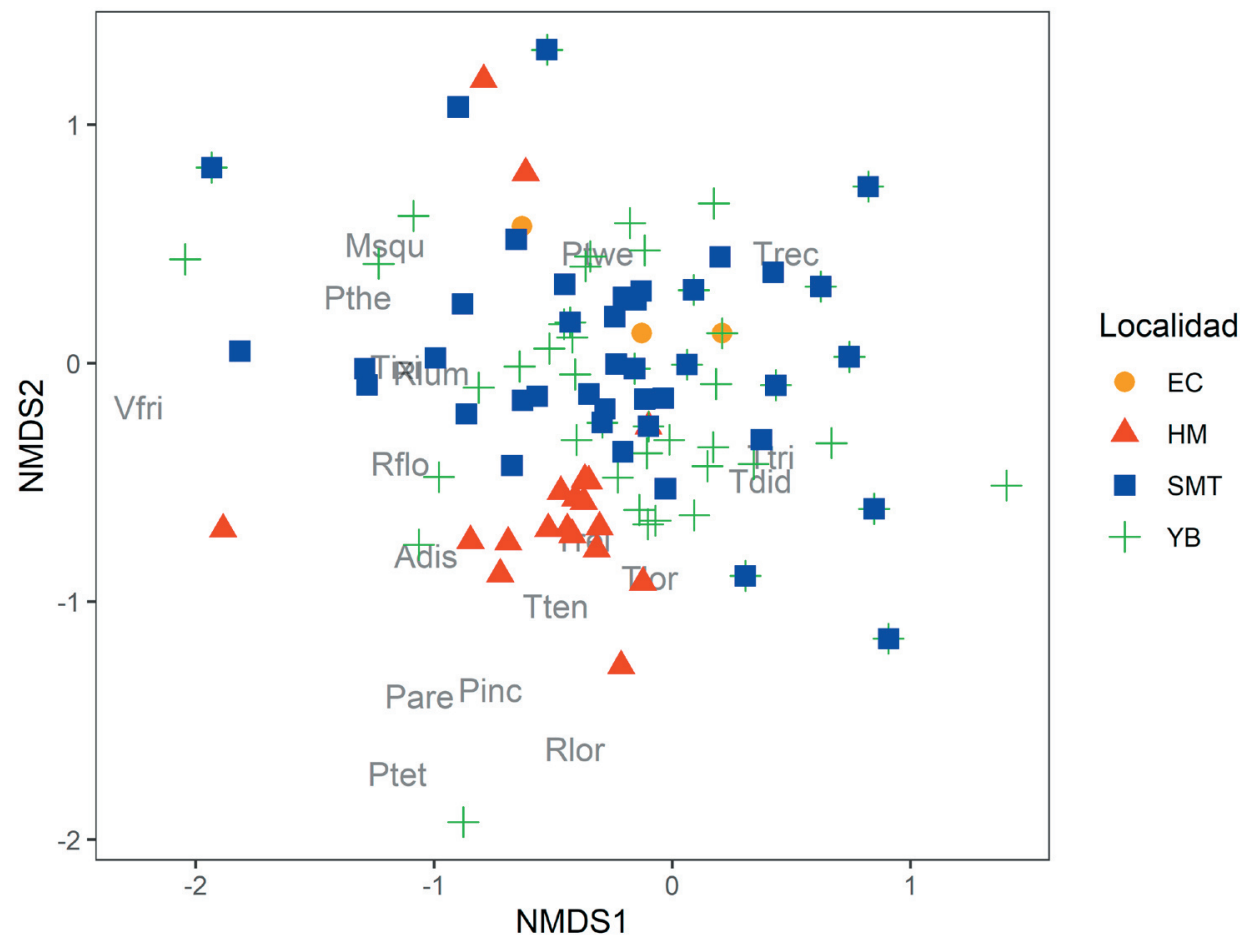

Figura 4. NMDS sobre la composición de especies de epífitas en los sectores de Horco Molle (HM) y El Corte (EC) y las ciudades de Yerba Buena (YB) y San Miguel de Tucumán (SMT). Las etiquetas representan a las especies de epífitas (códigos en la tabla 2) y los símbolos representan a los árboles en cada localidad.

Figure 4. NMDS showing the composition of epiphyte species in the localities of Horco Molle (HM) and El Corte (EC) and the cities of Yerba Buena (YB) and San Miguel de Tucuman (SMT). Labels represent species (see Table 2 for the species code) and symbols represent the individual trees per locality/city. 
epífitas. En el NMDS, cercanas a los puntos de estos sectores de la ciudad se encuentran las especies de epífitas más comúnmente observadas, como Microgramma squamulosa, Pleopeltis tweediana y Tillandsia recurvata.

\section{Discusión}

En este estudio se observó que la riqueza y la cobertura de epífitas vasculares que habitan el arbolado urbano del Gran San Miguel de Tucumán están determinadas principalmente por las características de los árboles hospedadores. La riqueza de especies y la cobertura aumentaron con el tamaño de los árboles (i.e., medido como diámetro a la altura del pecho) y con la rugosidad de la corteza. Ambas características de los árboles son conocidas por su importancia para las epífitas (Johansson 1974; Burns 2008). Los árboles de mayor tamaño proveen más superficie de corteza y diversidad de microhábitats, y generalmente son longevos, por lo que son colonizados por muchas especies de epífitas (Hietz and Hietz-Seifert 1995; Burns 2008; Woods et al. 2015). Una corteza más rugosa o agrietada presenta fisuras que permiten la acumulación de agua, nutrientes y materia orgánica, fundamentales para el establecimiento y crecimiento de las epífitas (Johansson 1974; Callaway et al. 2002). En bosques primarios de la sierra de San Javier (Tucumán), tanto el tamaño como la rugosidad de la corteza de los árboles determinaron un mayor número de interacciones entre epífitas y árboles hospedadores (Ceballos et al. 2016). Por lo tanto, se puede observar que en este ambiente urbano ocurren interacciones entre las epífitas y el arbolado similares a las que tienen lugar en bosques más prístinos.

El porcentaje de árboles colonizados por epífitas en el Gran San Miguel de Tucumán fue mayor que los porcentajes reportados previamente en los bosques subtropicales nativos de la región de Yungas (41-78\% de los árboles colonizados en diferentes tipos de bosque) (Brown 1990; Roldán 1995; Ceballos 2020). Sin embargo, es posible que esto se deba a que en la ciudad, los árboles están aislados y sus copas se pueden observar más fácilmente desde diferentes distancias para registrar todas las epífitas, mientras que en los muestreos en bosques de Yungas no es tan fácil observar parte de las copas debido a la superposición de estratos vegetales (e.g., se pueden perder registros de varias especies que habitan la copa externa, como las Tillandsia).
La composición de epífitas en el arbolado urbano estuvo dominada por especies del género Tillandsia, que se distribuyeron en todo el gradiente de urbanización. Estas especies son comúnmente denominadas heliófilas o bromelias atmosféricas porque poseen adaptaciones para tolerar una alta exposición lumínica y condiciones de desecación (Cascante-Marín et al. 2008; Woods 2017). Por ejemplo, se las encuentra con frecuencia en ramas finas, en la parte externa de la copa de los árboles e, incluso, en el cableado urbano, donde las condiciones de desecación son más severas (Brown 1986; Caldiz et al. 1993). También tienen la capacidad de colonizar un amplio rango de condiciones ambientales, ya que se las encuentra en bosques maduros, sucesionalmente secundarios tempranos y disturbados (Brown 1986; Cascante-Marín et al. 2006; Cascante-Marín et al. 2008; Padilha et al. 2017; Ceballos 2020). Pleopeltis tweediana fue otra de las especies más frecuentes en el arbolado urbano, conocida por ser reviviscente (i.e., sobrevive en condiciones extremas de insolación y evaporación durante un tiempo prolongado) (Brown 1986). De modo similar a las especies del género Tillandsia, Pleopeltis tweediana puede colonizar diferentes tipos de bosques, incluso parches de bosque disturbados y sucesionalmente tempranos (Brown 1986; Ceballos 2020). La dominancia de estas especies era predecible dada su capacidad para colonizar diferentes tipos de ambientes y las condiciones ambientales en las que se encuentran los árboles sobre los que habitan en la ciudad (i.e., altas temperaturas y menor humedad).

La riqueza de epífitas disminuyó a medida que aumentó la distancia a la sierra de San Javier, lo cual puede estar relacionado con varios factores. A medida que aumenta la distancia a la sierra de San Javier, la humedad disminuye y la temperatura aumenta en la ciudad, lo que puede representar condiciones adversas para algunas especies de epífitas. La presencia de árboles remanentes de gran tamaño, importantes hospedadores de epífitas (Köster et al. 2009; Larrea and Werner 2010) y que aún se encuentran en Horco Molle y El Corte, también podría explicar el aumento de la riqueza de epífitas hacia la sierra de San Javier. La sierra actuaría como fuente colonizadora de especies de epífitas de Yungas (Brown 1990; Roldán 1995; Ceballos et al. 2016; Ceballos 2020), principalmente hacia sectores del Gran San Miguel de Tucumán más cercanos a la sierra, como Horco Molle, El Corte y Yerba 
Buena, lo cual también podría explicar el patrón observado. Sin embargo, es importante aclarar que las especies Tillandsia lorentziana y Tillandsia reichenbachii que fueron registradas en este estudio no se observaron en muestreos previos realizados en la sierra de San Javier (Roldán 1995; Ceballos 2020), por lo que otros tipos de bosques o coberturas podrían influir sobre la composición de epífitas que habitan el arbolado urbano. Debido a la ausencia de remanentes de bosques dentro de una ciudad muy urbanizada, las plazas y parques podrían representar un tipo de cobertura determinante en la composición de epífitas. En este sentido, se observó que la cercanía a espacios verdes en la ciudad mostró una tendencia a incrementar la riqueza de epífitas en el arbolado urbano.

Puesto que es una primera aproximación al conocimiento de las epífitas en un ambiente urbano, este estudio presenta algunas limitaciones. Primero, registramos las epífitas con binoculares desde el suelo, sin trepar a los árboles, lo cual puede llevar a subestimar la riqueza de especies (Wolf et al. 2009). Sin embargo, las epífitas fueron fácilmente observables debido a que en la ciudad los árboles están aislados unos de otros y sus copas no se suelen superponer, por lo que la subestimación de la riqueza podría ser baja. Segundo, realizamos una ponderación de la cobertura de especies de epífitas con el DAP de los árboles para representar su abundancia relativa, aunque no es una medida verdadera del número de individuos de epífitas. Este aspecto metodológico pudo estar relacionado con que no detectamos diferencias significativas entre la cobertura de epífitas y el número de ramas podadas. Incorporar una medida de abundancia verdadera permitiría detectar, ante un mayor número de ramas podadas, una disminución del número de individuos de epífitas debido a la reducción del hábitat de corteza. Tercero, incluimos un set de variables para explicar la riqueza y la cobertura de epífitas, pero otras variables no contempladas podrían ser importantes para evaluar este sistema, como el tiempo de establecimiento del arbolado urbano y la contaminación atmosférica en la ciudad. En conclusión, este estudio representa una primera aproximación, y para aumentar el número de variables explicativas también se debería incrementar el número de sitios de muestreo.

Las epífitas presentan mayor diversidad en bosques primarios o maduros, pero también pueden colonizar nuevos ambientes como los bosques secundarios (Barthlott et al. 2001; Benavides et al. 2006; Woods and DeWalt 2013; Ceballos 2020) o el arbolado urbano, como se observó en este estudio. Si bien la ciudad representa un ambiente totalmente modificado, las características ecológicas de las epífitas en el arbolado urbano presentaron algunas similitudes con respecto a lo que se conoce sobre epífitas en bosques primarios. Por ejemplo, la importancia de las características de los árboles (i.e., tamaño y rugosidad de la corteza), de las especies arbóreas nativas y de la cercanía a las fuentes de propágulos (i.e., la sierra de San Javier) para las epífitas eran conocidas para bosques de Yungas (Ceballos et al. 2016; Ceballos 2020), y fueron similares en el ambiente urbano. Estos resultados son de suma importancia para planificar la conservación de epífitas nativas de Yungas en el arbolado urbano del Gran San Miguel de Tucumán, lo cual implica mantener los árboles de mayor diámetro, la preferencia de la forestación con especies de corteza rugosa o agrietada y la importancia de la conectividad entre fuentes de propágulos para favorecer la dispersión de epífitas. En las últimas décadas, el Gran San Miguel de Tucumán tuvo un crecimiento demográfico importante que llevó a perder espacios verdes en la periferia (Haedo et al. 2010; Gutiérrez-Angonese and Grau 2014); sin embargo, representa un ambiente transformado que se puede considerar una oportunidad para conservar epífitas nativas en el arbolado urbano.

Agradecimientos. Este trabajo estuvo enmarcado dentro del programa P.E.Ca.R.I.E.S (Programa de Entrenamiento y Capacitación de Recursos para la Investigación Ecológica del Subtrópico) del Instituto de Ecología Regional (CONICET-UNT). Agradecemos a Y.G. Jiménez por la enseñanza en el análisis de imágenes satelitales empleando Sistemas de Información Geográfica. Finalmente, a familia y amigos que colaboraron en el trabajo de campo. 


\section{REFERENCIAS}

Arteaga, A. J. M., M. F. B. M. Thiersch, R. O. A. Valente, L. K. Bernardi, S. L. Vasconcelos, and C. R. Thiersch. 2019. Volumetric spatiality of wood in forest settlement using artificial neural networks with satellite images. Acta Agronómica 68:142-150. https://doi.org/10.15446/acag.v68n2.78945.

Avdan, U., and G. Jovanovska. 2016. Algorithm for automated mapping of land surface temperature using LANDSAT 8 satellite data. Journal of Sensors 2:1-8. https://doi.org/10.1155/2016/1480307.

Barbosa, S., A. Droste, and J. L. Schmitt.2015. Vascular epiphytes of the Atlantic Forest in the Sinos River basin, state of Rio Grande do Sul, Brazil: richness, floristic composition and community structure. Braz. Brazilian Journal of Biology 25:25-35. https://doi.org/10.1590/1519-6984.0913.

Bardhan, R., R. Debnath, and S. Bandopadhyay. 2016. A conceptual model for identifying the risk susceptibility of urban green spaces using geo-spatial techniques. Modeling Earth Systems and Environment 2:1-12. https://doi.org/ 10.1007/s40808-016-0202-y

Barthlott, W., V. Schmit-Neuerburg, J. Nieder, and S. Engwald.2001. Diversity and abundance of vascular epiphytes: a comparison of secondary vegetation and primary montane rain forest in the Venezuelan Andes. Plant Ecology 152: 145-156. https://doi.org/10.1023/A:1011483901452.

Barton, K. 2009. MuMIn: multi-model inference. URL: r-forge.r-project.org/projects/mumin/.

Bates, D., M. Maechler, B. Bolker, and S. Walker. 2015. Fitting Linear Mixed-Effects Models Using lme4. Journal of Statistical Software 67(1):1-48. https://doi.org/10.18637/jss.v067.i01.

Becker, D. F. P., R. Linden, and J. L. Schmitt. 2017. Richness, coverage and concentration of heavy metals in vascular epiphytes along an urbanization gradient. Science of the Total Environment 584-585:48-54. https://doi.org/10.1016/ j.scitotenv.2017.01.092.

Benavides, A. M., J. H. D. Wolf, and J. F. Duivenvoorden. 2006. Recovery and succession of epiphytes in upper Amazonian fallows. Journal of Tropical Ecology 22:705-717. https://doi.org/10.1017/S0266467406003580.

Bermúdez, G. M. A., J. H. Rodríguez, and M. L. Pignata. 2009. Comparison of the air pollution biomonitoring ability of three Tillandsia species and the lichen Ramalina celastri in Argentina. Environmental Research 109:6-14. https: //doi.org/10.1016/j.envres.2008.08.014.

Bhandari, A. K., A. Kumar, and G. K. Singh. 2012. Feature Extraction using Normalized Difference Vegetation Index (NDVI): A Case Study of Jabalpur City. Procedia Technology 6:612-621. https://doi.org/10.1016/j.protcy.2012.10.074.

Bhatt, A., S. Gairola, Y. Govender, H. Baijnath, and S. Ramdhani. 2015. Epiphyte diversity on host trees in an urban environment, eThekwini Municipal Area, South Africa. New Zealand Journal of Botany 53:24-37. https://doi.org/ 10.1080/0028825X.2014.1000935.

Boelter, C. R., C. S. Dambros, H. E. M. Nascimento, and C. E. Zartman. 2014. A tangled web in tropical tree-tops: Effects of edaphic variation, neighbourhood phorophyte composition and bark characteristics on epiphytes in a central Amazonian forest. Journal of Vegetation Science 25:1090-1099. https://doi.org/10.1111/jvs.12154.

Böhnert, T., A. Wenzel, C. Altenhövel, L. Beeretz, S. Tjitrosoedirdjo, A. Meijide, K. Rembold, and H. Kreft. 2016. Effects of land-use change on vascular epiphyte diversity in Sumatra (Indonesia). Biological Conservation 202:20-29. https: //doi.org/10.1016/j.biocon.2016.08.008.

Bomba, H., R. Caminos, M. Casares, and R. Di Lullo. 2007.Perspectivas del medio ambiente urbano. GEO San Miguel de Tucumán. Ed. PNUMA. https://doi.org/10.14409/pampa.v1i3.3141.

Brown, A. D. 1986. Autoecología de bromeliáceas epífitas del NO argentino y su relación con Cebus apella. Tesis doctoral. Universidad Nacional de La Plata, Buenos Aires. Argentina. Pp. 474.

Brown, A. D. 1990. El epifitismo en las selvas montanas del Parque Nacional “El Rey” Argentina: Composición florística y padrón de distribución. Revista de Biología Tropical 38:155-166.

Burns, K. C. 2008. Meta-community structure of vascular epiphytes in a temperate rainforest. Botany 86:1252-1259. https://doi.org/10.1139/B08-084.

Caldiz, D. O., J. Beltrano, L. V. Fernández, and I. Andía. 1993. Survey of Tillandsia recurvata L.: preference, abundance and its significance for natural forests. Forest Ecology and Management. 57:161-168. https://doi.org/10.1016/03781127(93)90169-N.

Callaway, R. M., K. O. Reinhart, G. W. Moore, D. J. Moore, and S. C. Pennings. 2002. Epiphyte host preferences and host traits: mechanisms for species-specific interactions. Oecologia 132:221-230. https://doi.org/10.1007/s00442-0020943-3.

Cascante-Marín, A., J. H. D. Wolf, J. G. B. Oostermeijer, J. C. M. den Nijs, O. Sanahuja, and A. Durán Apuy. 2006. Epiphytic bromeliad communities in secondary and mature forest in a tropical premontane area. Basic and Applied Ecology 7:520-532. https://doi.org/10.1016/j.baae.2005.10.005.

Cascante-Marín, A., J. H. D Wolf, J. G. B. Oostermeijer, and J. C. M Den Nijs. 2008. Establishment of epiphytic bromeliads in successional tropical premontane forests in Costa Rica. Biotropica 40(4):441-448. https://doi.org/10.1111/j.17447429.2008.00403.x.

Cao, Y., and Y. Natuhara. 2020. Effect of urbanization on vegetation in riparian area: Plant communities in artificial and semi-natural habitats. Sustainability (Switzerland) 12(1):204. https://doi.org/10.3390/su12010204.

Ceballos, S. J., N. P. Chacoff, and A. Malizia. 2016. Interaction network of vascular epiphytes and trees in a subtropical forest. Acta Oecologica 77:152-159. https://doi.org/10.1016/j.actao.2016.10.007.

Ceballos, S. J. 2020. Vascular epiphyte communities in secondary and mature forests of a subtropical montane area. Acta Oecologica 105:103571. https://doi.org/10.1016/j.actao.2020.103571. 
Colding, J. 2007. “Ecological land-use complementation” for building resilience in urban ecosystems. Landscape Urban Planning 81:46-55. https://doi.org/10.1016/j.landurbplan.2006.10.016.

Cuozzo, R. L., and A. L. Castañeda Nordmann. 2019. Problemas ambientales y su incidencia en la calidad Urbana residencial. Estudio del caso. XIII Jornadas de Sociología. Facultad de Ciencias Sociales, Universidad de Buenos Aires, Buenos Aires, Argentina.

El-Gammal, M., R. Ali, and R. M Abou Samra. 2014. NDVI Threshold Classification for Detecting Vegetation Cover in Damietta Governorate, Egypt. Journal of American Science 10:108-113.

Gioia, A., L. Paolini, A. Malizia, R. Oltra-Carrió, and J. A. Sobrino. 2014. Size matters: vegetation patch size and surface temperature relationship in foothills cities of northwestern Argentina. Urban Ecosystems 17:1161-1174. https: //doi.org/10.1007/s11252-014-0372-1.

Graciano, C., L. V. Fernández, and D. O. Caldiz. 2003. Tillandsia recurvata L. as a bioindicator of sulfur atmospheric pollution. Ecología Austral 13:3-14.

Grau, H. R. 2010. Ecología de una interfase natural-urbana. La sierra de San Javier y el Gran San Miguel de Tucumán. Editorial de la Universidad Nacional de Tucumán, Tucumán, Argentina.

Grau, A., and A. Kortsarz. 2017. Guía de Arbolado de Tucumán. 2ª Edición. Editorial de la Universidad Nacional de Tucumán, Tucumán, Argentina.

Gross, D. 2005. Monitoring Agricultural Biomass Using NDVI Time Series. Food and Agriculture Organization of the United Nations (FAO), Rome, Italy.

Guida-Johnson, B., A. M. Faggi, and G. A. Zuleta.2017. Effects of Urban Sprawl on Riparian Vegetation: Is Compact or Dispersed Urbanization Better for Biodiversity? River Research and Applications 33:959-969. https://doi.org/10.1002/ rra.3138.

Gutiérrez-Angonese, J., and H. R. Grau. 2014. Assessment of swaps and persistence in land cover changes in a subtropical periurban region, NW Argentina. Landscape and Urban Planning 127:83-93. https://doi.org/10.1016/ j.landurbplan.2014.01.021.

Haedo, J., P. G. Blendinger, and N. I. Gasparri. 2010. Estructura espacial del ensamble de aves en el gradiente de urbanización de Yerba Buena-San Miguel de Tucumán, noroeste de Argentina. Pp. 153-166 en H. R. Grau (ed.). Ecología de una interfase natural-urbana. La sierra de San Javier y el Gran San Miguel de Tucumán. Editorial de la Universidad Nacional de Tucumán, Tucumán, Argentina.

Haedo, J., A. Gioia, E. Aráoz, L. Paolini, and A. Malizia. 2017. Primary productivity in cities and their influence over subtropical bird assemblages. Urban Forestry and Urban Greening 26:57-64. https://doi.org/10.1016/ j.ufug.2017.04.017.

Hashim, H., Z. Abd Latif, and N. A. Adnan. 2019. Urban vegetation classification with ndvi threshold value method with very high resolution (VHR) pleiades imagery International_Archives of the Photogrammetry, Rempte Sensing and Spatial Information Sciences 16:237-240. hittps://doi.org/10.5194/isprs-archives-XLII-4-W16-237-2019.

Hernández, H. J., and N. R. Villaseñor. 2018. Twelve-year change in tree diversity and spatial segregation in the Mediterranean city of Santiago, Chile. Urban Forestry and Urban Greening 29:10-18. https://doi.org/10.1016/ j.ufug.2017.10.017.

Hietz, P., and U. Hietz-Seifert. 1995. Structure and ecology of epiphyte communities of a cloud forest in central Veracruz, Mexico. Journal of Vegetation Science 6:719-728. https://doi.org/10.2307/3236443.

Higuera, D., and J. H. D. Wolf. 2010. En Bosques Secos de roble las epífitas vasculares muestran resistencia a la alteración humana, Cordillera Oriental, Colombia. Caldasia 32:161-174.

Hope, D., C. Gries, W. Zhu, W. F. Fagan, C. L. Redman, N. B. Grimm, A. L. Nelson, C. Martin, and A. Kinzig. 2008. Socioeconomics drive urban plant diversity. Urban Ecology: An International Perspective on the Interaction between Humans and Nature 100:339-347. https://doi.org/10.1007/978-0-387-73412-5_21.

INDEC. 2010. Censo Nacional de Población, Hogares y Viviendas.

Jankowski, L., D. Bazzano, A. Sáenz, M. Tourn, and G. Roitman. 2000. Plantas trepadoras nativas y exóticas. L.O.L.A., Buenos Aires, Argentina.

Jarvis, M. T. 2000. Measuring and modelling the impact of land-use change in tropical hillsides: the role of cloud interception to epiphytes. Advances in Environmental Monitoring and Modelling 1:118-148.

Johansson, D. 1974. Ecology of vascular epiphytes in West African rain forest. Acta Phytogeographica Suecica 59: $1-136$.

Knapp, S., I. Kühn, J. P. Bakker, M. Kleyer, S. Klotz, W. A. Ozinga, P. Poschlod, K. Thompson, W. Thuiller, and C. Römermann. 2009. How species traits and affinity to urban land use control large-scale species frequency. Diversity and Distributions 15:533-546. https://doi.org/10.1111/j.1472-4642.2009.00561.x.

Kortsarz, A., and S. Gómez Romero. 2017. Arriba de los árboles urbanos: plantas epífitas y parásitas. Pp. 249-253 en A. Grau and A. Kortsarz (eds.). Guía de Arbolado de Tucumán. 2ª Edición. Editorial de la Universidad Nacional de Tucumán, Tucumán, Argentina.

Köster, N., K. Friedrich, J. Nieder, and W. Barthlott. 2009. Conservation of epiphyte diversity in an Andean landscape transformed by human land use. Conservation Biology 23(4):911-919. https://doi.org/10.1111/j.15231739.2008.01164.x.

Larrea, M. L., and F. A. Werner. 2010. Response of vascular epiphyte diversity to different land-use intensities in a neotropical montane wet forest. Forest Ecology and Management 260(11):1950-1955. https://doi.org/10.1016/ j.foreco.2010.08.029.

Lenth, R. 2020. Emmeans: Estimated Marginal Means, aka Least-Squares Means. R package version 1.4.5. URL: CRAN.R-project.org/package=emmeans.

Martins Luiz, P., S. Silva, M. Samyra, G. Furtado, and L. M. Neto. 2020. Could epiphytes be xenophobic? Evaluating the use of native versus exotic phorophytes by the vascular epiphytic community in an urban environment. Community Ecology 21:91-101. https://doi.org/10.1007/s42974-020-00001-y.

Mendieta-Leiva, G., and G. Zotz. 2015. A conceptual framework for the analysis of vascular epiphyte assemblages. Perspectives in plant ecology, evolution and systematics 17(6):510-521. https://doi.org/10.1016/j.ppees.2015.09.003. 
Niemelä, J., S. R. Saarela, T. Söderman, L. Kopperoinen, V. Yli-Pelkonen, S. Väre, and D. J. Kotze. 2010. Using the ecosystem services approach for better planning and conservation of urban green spaces: A Finland case study. Biodiversity Conservation 19:3225-3243. https://doi.org/10.1007/s10531-010-9888-8.

Oksanen, J., R. Kindt, P. Legendre, B. O’Hara, G. L. Simpson, P. Solymos, M. Henry, H. Stevens, and H. Wagner. 2007. The vegan package. Community ecology package 10:631-637.

Oltra-Carrió, R., J. A. Sobrino, J. Gutiérrez-Angonese, A. Gioia, L. Paolini, and A. Malizia. 2010. Estudio del crecimiento urbano, de la estructura de la vegetación y de la temperatura de la superficie del Gran San Miguel de Tucumán, Argentina. Revista de Teledetección 34:69-76.

Padilha, P. T., G. A. Elias, R. S. Santos, R. Martins, and V. Citadini-Zanette. 2017. Vascular epiphytes respond to successional stages and microhabitat variations in a subtropical forest in southern Brazil. Brazilian Journal of Botany 40(4):897-905. https://doi.org/10.1007/s40415-017-0391-2.

Padmawathe, R., Q. Qureshi, and G. S. Rawat. 2004. Effects of selective logging on vascular epiphyte diversity in a moist lowland forest of Eastern Himalaya, India. Biological Conservation 119:81-92. https://doi.org/10.1016/ j.biocon.2003.10.024.

Planchuelo, G., M. Von Der Lippe, and I. Kowarik. 2019. Untangling the role of urban ecosystems as habitats for endangered plant species. Landscape Urban Planning 189:320-334. https://doi.org/10.1016/j.landurbplan.2019.05.0 07 .

QGIS Development Team. 2016. QGIS Geographic Information System. Open-Source Geospatial Foundation Project. URL: qgis.osgeo.org.

R Development Core Team. 2021. R: A language and environment for statistical computing. R Foundation for Statistical Computing, Vienna, Austria. URL: R-project.org.

Rahman, S., and V. Mesev. 2019. Change vector analysis, tasseled cap, and NDVI-NDMI for measuring land use/ cover changes caused by a sudden short-term severe drought. Remote Sensing 11:1-21. https://doi.org/10.3390/ rs11192217.

Roldán, A. I. 1995. Estructura de sitios disturbados y no disturbados de las selvas montanas de la sierra de San Javier (Tucumán, Argentina). Lilloa 38(2):133-156.

Rosell, P., and M. Vicente. 2016. Análisis del crecimiento demográfico y la relación entre espacios verdes y edificados en Darregueira fon QGIS. Conferencia de Geomática Libre, Buenos Aires, Argentina. https://doi.org/10.13140 RG.2.1.2863.7687

Santana, L. D., S. Gomes Furtado, C. Nardy, F. S. Leite, and L. M. Neto. 2017. Diversity, vertical structure and floristic relationships of vascular epiphytes in an urban remnant of the Brazilian Atlantic Forest. Hoehnea 44:123-138. https: //doi.org/10.1590/2236-8906-57/2016.

Senanayake, I. P., W. D. D. P. Welivitiya, and P. M. Nadeeka. 2013. Urban green spaces analysis for development planning in Colombo, Sri Lanka, utilizing THEOS satellite imagery - A remote sensing and GIS approach. Urban Forestry and Urban Greening 12:307-314. https://doi.org/10.1016/j.ufug.2013.03.011.

Spescha, V. 2019. Relaciones entre espacios verdes e indicadores socioeconómicos en ambientes urbanos de San Miguel de Tucumán. Tesina de grado. Universidad Nacional de Tucumán, Tucumán. Argentina. Pp. 476.

Stanton, D. E., J. H. Chávez, L. Villegas, F. Villasante, J. J. Armesto, L. O. Hedin, and H. H. Horn. 2014. Epiphytes improve host plant water use by microenvironment modification. Functional Ecology 28:1274-1283. https://doi.org/ 10.1111/1365-2435.12249.

Tzoulas, K., K. Korpela, S. Venn, V. Yi-Pelkonen, A. Kaźmierczak, J. Niemela, and P. James. 2007. Promoting ecosystem and human health in urban areas using Green Infrastructure: A literature review. Landscape and Urban Planning 81:167-178. https://doi.org/10.1016/j.landurbplan.2007.02.001.

Van der Walt, L., S. S. Cilliers, M. J. Du Toit, and K. Kellner. 2015. Conservation of fragmented grasslands as part of the urban green infrastructure: how important are species diversity, functional diversity and landscape functionality? Urban Ecosystem 18:87-113. https://doi.org/10.1007/s11252-014-0393-9.

Victoriano-Romero, E., S. Valencia-Díaz, V. H. Toledo-Hernández, and A. Flores-Palacios. 2017. Dispersal limitation of Tillandsia species correlates with rain and host structure in a central Mexican tropical dry forest. PLoS One 12:1-16. https://doi.org/10.1371/journal.pone.0171614.

Vindas, S. B. 2005. El Sector Turismo: Su Aporte a La Economía. Economia y Sociedad 10(27):111-121.

Wallace, K. J., D. C. Laughlin, and B. D. Clarkson. 2017. Exotic weeds and fluctuating microclimate can constrain native plant regeneration in urban forest restoration. Ecological Applications 27:1268-1279. https://doi.org/10.1002/ eap. 1520 .

Wolf, J. H. D., S. R. Gradstein, and N. M. Nadkarni. 2009. A protocol for sampling vascular epiphyte richness and abundance. Journal of Tropical Ecology 25:107-121. https://doi.org/10.1017/S0266467408005786.

Woods, C. L., and S. J. DeWalt. 2013. The conservation value of secondary forests for vascular epiphytes in Central Panama. Biotropica 45(1):119-127. https://doi.org/10.1111/j.1744-7429.2012.00883.x.

Woods, C. L., C. L. Cardelús, and S. J. Dewalt. 2015. Microhabitat associations of vascular epiphytes in a wet tropical forest canopy. Journal of Ecology 103:421-430. https://doi.org/10.1111/1365-2745.12357.

Woods, C. L. 2017. Primary ecological succession in vascular epiphytes: The species accumulation model. Biotropica 49(4):452-460. https://doi.org/10.1111/btp.12443.

Yang, J., F. A. La Sorte, P. Pyšek, P. Yan, D. Nowak, and J. Mcbride. 2015. The compositional similarity of urban forests among the world's cities is scale dependent. Global Ecology and Biogeography 24:1413-1423. https://doi.org/10.1111/ geb.12376.

Zotz, G. 2016. Plants on Plants - The Biology of Vascular Epiphytes.1. Springer International Publishing, Berlín, Alemania. https://doi.org/10.1007/978-3-319-39237-0_1. 